\title{
SOBRE LA ESTÉTICA DE LA IMPOSTURA: SE BUSCAN FALSIFICADORES DE LA NOVELA ACTUAL
}

\author{
Teresa Gómez Trueba \\ (Universidad de Valladolid)
}

\section{Prólogo con «instrucciones de uso»}

En 2016 la videoartista Marla Jacarilla expuso en Madrid un montaje titulado Manual de instrucciones para interpretar falsas novelas, que a su vez pertenecía a su serie Elucubraciones en torno a esa serie de características que debería tener -o no- la literatura del futuro'. Esta obra conceptual crea un irónico manual, a modo de videoinstalación instructiva, que sirve para interpretar la «falsa literatura» y más concretamente las Seis falsas novelas escritas por Ramón Gómez de la Serna entre 1923 y 1927. La obra de este contenía seis relatos breves en los que el escritor plagiaba irónicamente lo que él mismo consideraba diversos estilos literarios. Según explica Jacarilla en la presentación de su obra, esta se propone reflexionar sobre «la impostura en la literatura y en el arte, sobre el papel de los museos o sobre conceptos como copia, apropiación, plagio o reinterpretación» (2016). El irónico título de la obra de Jacarilla y el hecho de que recupere desde el videoarte contemporáneo esa interesante obra de la Vanguardia española pone de manifiesto lo asimilada y extendida que hoy en día parece estar la idea de que la novela no es ya muchas veces lo que aparenta ser. Y es que ahora más que nunca las novelas juegan a despistar a los lectores, ocultándose bajo el disfraz de otros géneros literarios y haciendo de la falsedad, el engaño y la impostura uno de los valores estéticos más interesantes de nuestros días. Parece ya una verdad asumida por la crítica la naturaleza extremadamente porosa y multiforme de la novela actual y su propensión a mezclarse y confundirse con otros géneros literarios. Concretamente, son numerosísimas las novelas que desdibujan sus perfiles en

\footnotetext{
1 La obra se presentó en la exposición Multiverso.Videoarte (Madrid, 2016), organizada y financiada por la Fundación BBVA.
} 
relación con el género del ensayo. Los ensayos novelados, las novelas con tono ensayístico, han dejado desde hace tiempo de ser una anomalía en las librerías. Pero la forma en la que el ensayo se cuela y manifiesta en las novelas no siempre es la misma. Los extremos de desconcierto a los que en la narrativa actual puede llevarnos ese consabido «pacto ambiguo» (Alberca 2007) de la voz narradora que se complace en jugar al despiste, identificándose de manera intermitente y poco fiable con la voz del autor, dan como resultado un amplísimo abanico de posibilidades al respecto. Encontraremos así infinidad de novelas en las que un levísimo marco ficcional justifica una voz que divaga y deambula en interminables digresiones de tono ensayístico por los más diversos asuntos. Y ese caminar sin rumbo conduce generalmente al autor a la última e íntima finalidad de narrarse, pues, como diría Montaigne al comienzo de sus Essais, es hoy en día muchas veces el mismo autor el primer «objeto de su libro». En este contexto, no son pocas las novelas que parecen surgir como comentarios de obras anteriores del propio autor, reflexionando y, en ocasiones, discutiendo sobre su recepción, lectura o interpretación, inscribiendo así cada nuevo libro de su producción en un bucle autorreferencial inasible y sin fin. Entre las novelas híbridas y con tendencia a lo metaficcional son también ya legión las que incluyen (a modo de notas a pie de página, prólogos, epílogos o estudios complementarios) paratextos apócrifos que forman en realidad, y sin parecerlo a simple vista, parte del mismo entramado ficcional. Pues bien, dejando estas posibilidades discursivas para otros trabajos, en este artículo nos detendremos a analizar la que creo que podemos considerar también una no infrecuente estrategia que permite incluir en el marco de una novela contenidos de carácter ensayístico. Me refiero a las novelas que se presentan bajo el aspecto y la estructura externa del catálogo, diccionario, enciclopedia o manual; es decir, que se disfrazan bajo la engañosa apariencia del libro erudito o la obra de referencia. Este tipo de estrategia se inscribe dentro de lo que podríamos considerar una estética de la simulación y la impostura, en relación con la cual conviene traer aquí una oportuna reflexión de Alberca:

\footnotetext{
El fenómeno actual no se caracteriza ya por la inclusión de elementos autobiográficos o fragmentos históricos en una estructura novelesca, como podía ocurrir en la novela autobiográfica o en la novela histórica de inspiración decimonónica. No, no se trata solo del uso ocasional de éstos para dar mayor verosimilitud a la novela, sino de la construcción entera de la novela como un simulacro autobiográfico o histórico. Tampoco se trata de la apropiación de tal o cual elemento aislado
} 
tomado de aquí o de allá, sino de la invasión colonialista de los géneros de no-ficción por la ficción hasta dejarlos irreconocibles (Alberca 2007: 287).

Así, estudiaré en este artículo algunas novelas que no sólo adoptan determinados recursos propios de otros géneros, sino que se presentan al completo como simulacros de «Obras de referencia». Según leemos en Wikipedia estas «son documentos de consulta que sirven para resolver dudas puntuales. No están concebidas para su lectura completa sino para consultas rápidas sobre un determinado dato. Obras de referencia son los diccionarios, glosarios, vocabularios, léxicos, terminologías, enciclopedias, atlas, directorios...». Analizaremos en un primer apartado algunas novelas cuya apariencia nos invita a este tipo de lectura. Asimismo, y a modo de "Addenda», hablaremos de algunas novelas recientes que han reemplazado la Enciclopedia tradicional por Wikipedia, simulando ser el resultado de una búsqueda o navegación por Google e incluyendo los textos (muchas veces de carácter ensayístico) con los que el narrador se ha ido topando en la misma. Dos pactos ficcionales que justifican con frecuencia el hallazgo de un ensayo en las entrañas de la ficción.

\section{La Novela-Enciclopedia}

Desde la mítica Historia universal de la infamia (1935) de Borges, han sido muchos los escritores que han enmascarado sus ficciones bajo la apariencia del libro erudito. Pensemos, a modo de ejemplo, en varios títulos muy populares de la literatura portuguesa contemporánea, tales como el Manual de pintura y caligrafía (1977), el Ensayo sobre la ceguera (1995) o el Ensayo sobre la lucidez (2004) de José Saramago, el Tratado de las pasiones del alma (1990) o el Manual de inquisidores (1996) de Lobo Antunes. En el contexto de la literatura española, el Pequeño manual de las madres del mundo (2003), de Gustavo Martín Garzo, parece seguir la misma estrategia. Más recientemente, la edición póstuma de los cuentos de la admirada Lucía Berlín, bajo un título que es fruto de la decisión de sus editores, Manual para mujeres de la limpieza (2015), pone aún mejor en evidencia lo que parece ser un fenómeno en auge.

Pero si en algunos casos es sólo un título mejor o peor justificado en el interior del libro, en otros el disfraz de la obra erudita trasciende también a la estructura externa de la novela, apareciendo incluso en los títulos de las diferentes secciones y capítulos que la componen. Me 
refiero a obras cuya estructura nos está invitando irónicamente a un tipo de lectura «salteada», más propia de una obra de referencia que de una novela. Tal es, por ejemplo, el caso del conocido Diccionario Jázaro (1989) de Milorad Pavic. Este se presenta y estructura como un diccionario o «novela léxico en 100.000 palabras», que a su vez está formado de otros tres diccionarios: el «Libro rojo», el «Libro verde» y el "Libro amarillo», donde se recogen respectivamente fuentes cristianas, islámicas y judías sobre la cuestión jázara. El libro, se nos advierte en las «Observaciones preliminares», puede leerse de innumerables maneras. $Y$, efectivamente, la peculiar novela artefacto de Pavic tiene artículos, concordancias y referencias; muchos nombres y conceptos aparecen marcados y pueden ser buscados en la parte correspondiente del diccionario para encontrar información más exhaustiva sobre ellos. En relación con esta estructura móvil, el autor nos asegura en el prólogo que el lector podrá reestructurar su novela y darle infinitas vueltas como si fuera un «Cubo de Rubik», dando además estas instrucciones para enfrentarse a ella:

\footnotetext{
No será necesario respetar cronología alguna. Así, cada lector podrá recomponer el propio libro en una unidad como en una partida de dominó o de naipes, y obtendrá de este diccionario, al igual que de un espejo, tanto cuanto invierta en el mismo. No es necesario por cierto que el libro se lea en su totalidad, puede tomarse la mitad o tan sólo una parte, y detenerse ahí, tal y como a menudo se hace con los diccionarios. Cuanto más se busque, más se recibirá y el descubridor afortunado contará con todos los lazos que relacionan los nombres de este diccionario (Pavic 2000: 22).
}

Sin llegar a estos extremos de complejidad estructural, en el contexto de la literatura española, podemos recordar la Gramática parda (1982) de Juan García Hortelano, cuyo título esconde una novela que se estructura en 33 "Lecciones», varios ejercicios, comentario de textos y un Apéndice, que simulan ser los diferentes capítulos de una peculiar gramática. Bajo dicha apariencia se esconde una divertida historia de ficción que, a su vez, encierra inteligentes reflexiones sobre la escritura. Muchos años después, Rafael Reig publicó un Manual de literatura para caníbales (2006), en el que se va pasando revista a un gran número de célebres escritores de la Historia de la Literatura española de los dos últimos siglos, convertidos aquí en personajes literarios. El resultado es como una especie de manual de la literatura española reciente, escrita en clave paródica. Y como todo manual incorpora notas a pie de página, listados bibliográficos e incluso una sección de «Ejercicios» al final de cada capítulo. 
La popularidad de novelas como la de Pavic ha contribuido a que ya pocos lectores se Ileven a engaño respecto a lo que se esconde bajo la apariencia de algunos títulos impostores. No obstante, creo que los casos más interesantes que nos ofrece el fenómeno aludido son aquellos en los que el disfraz erudito sigue consiguiendo una recepción ambigua de la obra en relación con su clasificación genérica. Naturalmente, esa posibilidad va decreciendo a medida que se incrementa el número de novelas que recurren a la misma estrategia. Cuando en la temprana fecha de 1977 José Saramago publicó su Manual de pintura y caligrafía, es muy posible que el propio título contribuyera a la escasa atención que, salvo excepciones, se prestó al mismo. Asimismo, es curioso comprobar como en algunas ediciones (Caminho, 1983; Seix Barral, 1989) justo debajo del título figuraba la palabra «Romance»o «Novela», a modo de advertencia para los lectores despistados (Belmonte Serrano y Guerrero Ruiz 2004: 24). Naturalmente, dicha advertencia es ya innecesaria, dada la popularidad del autor y sus obras, en la edición más reciente de Alfaguara (1999). Tampoco tendrá hoy en día ninguna duda respecto a la naturaleza ficcional de este sui géneris manual quien se asome a su interior, fundamentalmente teniendo en cuenta el ensanchamiento que en los últimos años hemos presenciado respecto a nuestra inestable concepción de lo que es ficción.

Me interesa detenerme ahora en algunas obras en las que, probablemente siguiendo el ejemplo de Borges, se introducen en el ámbito de la ficción determinadas estrategias discursivas y paratextos apócrifos que contribuyen a incrementar ese atractivo grado de ambigüedad del que hablamos. Me referiré a obras en las que de manera muy evidente, bajo el experimento formal propuesto, parece subyacer el convencimiento de que la Historia, la Enciclopedia, el Manual, y el discurso erudito que se les presupone a todos ellos, se construye a fin de cuentas con los mismos materiales que una Ficción.

En este sentido de cita obligada es la obra que para muchos críticos consolidó a Enrique Vila-Matas como un autor indispensable y enormemente influyente. Me refiero a su popular Historia abreviada de la literatura portátil (1985), novela en la que se ficcionaliza la escritura de una peculiar historia de la literatura. El narrador asume el papel de investigador y va relatando el resultado de sus pesquisas sobre la sociedad secreta shandy. Como toda obra erudita, esta se cierra con una «Bibliografía esencial», que naturalmente no es más que un paratexto apócrifo, que forma también parte de la novela. En este listado se mezclan referencias bibliográficas reales (así, 
por ejemplo, la de Jacques Rigaut, Agence générale du suicide, Le Terrain Vague, París 1967), con otras inventadas (como, por ejemplo, Ray Man, Travels with Rita Malú, Reynal and Hitchcock, Nueva York, 1947). De todas estas referencias el narrador extrae supuestamente las citas que van sucediéndose e interconectándose a lo largo de la novela. Pero, pese a las apariencias de veracidad, nada aquí es fiable. En un momento dado menciona el narrador-investigador una obra que dice servirle de modelo estético a la que él mismo está componiendo: la Historia portátil de la literatura abreviada de Tistan Tzara. En la bibliografía final se cita esta obra como parte de la edición Sept manifiestes Dadá. L'espion des realistes et una histoire inédite, J-J. Pauvert, París, 1963. Pero lo cierto es que en el interior de esta edición real de los manifiestos del Dadaísmo no se encuentra recogida la obra mencionada de Tristan Tzara, que por supuesto no existe (Oñoro 2015: 112). Como no podía ser de otra manera, desde la publicación de Historia abreviada de la literatura portátil, el mito de las citas falsas y los autores inventados se cierne sobre toda la obra vilamatiana haciéndola especialmente atractiva. El mismo autor ha contribuido, no sólo con sus novelas, sino también con sus declaraciones, a alentar esa leyenda (Vila-Matas 2008).

Otro ejemplo interesante sería La literatura nazi en América (1996) de Roberto Bolaño, novela que de nuevo se oculta bajo la engañosa apariencia de historia o diccionario de literatura. Según se nos informa en la misma contraportada, la obra es, en palabras de su autor: «una antología vagamente enciclopédica de la literatura filonazi producida en América desde 1930 a 2010». La novela se presenta así como un peculiar diccionario o manual de literatura, dividiéndose en 13 capítulos no numerados, que clasifican temáticamente a una serie de autores de los que se ofrece una breve ficha biográfica. Sin prólogo ni advertencias preliminares que nos ayuden a descubrir la impostura, la obra comienza bruscamente con la entrada correspondiente a una de las autoras reseñadas (Edelmira Thompson de Mendiluce). Cada una de las sucesivas entradas que siguen a esta ocupa entre las dos o diez páginas (dependiendo de la relevancia del personaje estudiado) y va encabezada, como en los verdaderos diccionarios de literatura, con los lugares y fechas de nacimiento y muerte del autor correspondiente. Pero, pese a las apariencias, que podrían engañar a muchos lectores, todos los autores reseñados son inexistentes. De hecho, las falsas biografías de Bolaño deberían de ser inscritas también en la literatura prospectiva y de anticipación, teniendo en cuenta que muchas de ellas sobrepasan largamente en el tiempo la propia fecha de publicación del libro. Por otro lado, como en la novela de Vila-Matas, o en la 
más obvia predecesora de ambas (la Historia universal de la infamia, de Borges), encontramos también aquí un listado de fuentes. En este caso, bajo el título de «Epílogo para monstruos», se nos ofrecen tres extensos índices, uno de personajes, otro de editoriales, revistas y lugares y un tercero de libros. Pero de nuevo toda la información recogida en estos índices de apariencia tan veraz es radicalmente falsa.

Tal y como ha señalado Rodríguez de Arce, todas las biografías que figuran en este corpus enciclopédico de la literatura nazi americana abundan en referencias literarias, culturales, políticas o históricas reales: «viven experiencias (la Segunda Guerra mundial, viajes por la Europa de la primera mitad del siglo XX, etc.) y entran en contacto con movimientos y artistas perfectamente reconocibles para un lector mínimamente competente» (Rodríguez de Arce 2009: 24). De esta manera, el desconcierto del lector aumenta cuando comprueba que el dato histórico real se combina con absoluta naturalidad con el dato inventado.

Cabría preguntarse qué persiguió Bolaño con esta extraña novela. En opinión de Rodríguez de Arce:

\footnotetext{
el texto es altamente representativo del Bolaño pasticheur; en éste, el chileno reduce el estilo de la vieja manualística biográfico-literaria a su armazón mismo, asimila perfectamente sus estilemas constitutivos y los imita. Sin embargo, el resultado tiene un efecto manifiestamente cómico porque el contenido (...) si bien escrito alla maniera de este tipo de manuales, no es el que se esperaría de un texto de esas características. El efecto cómico de algunas de las biografías que componen la obra reside, por tanto, en la inadecuación, en la incongruencia, entre la maniera de manual de autores literarios del texto y el contenido específico (de naturaleza altamente satírica) de las biografías de los escritores presentes en él (Rodríguez de Arce 2009: 25).
}

Asimismo, el crítico citado se esfuerza por demostrar cómo en esta obra encontramos también «ocasionales pero extraordinarias lecturas paródicas» (2009: 33) de obras concretas. Resulta curioso este interés del crítico por encontrar cuál es el libro parodiado, el modelo concreto de la falsificación de Bolaño. En este sentido, también Ilama la atención lo que Javier Avilés afirma en una reseña de la obra: «Quiero creer que existe un nexo entre la realidad y los autores que cita-crea Bolaño, como si fueran parte de un reflejo hermético de cuyas claves sólo participase el autor y, quizás, algunos de los que le conocieron en vida» (2005). Cuestión esta, la 
de la imposibilidad de concebir una copia sin modelo, a la que habré de volver más adelante.Sin negar las intenciones paródicas señaladas por Rodríguez de Arce y anheladas por Avilés, creo más bien que la obra de Bolaño habría de ser inscrita en esa tradición estética de la impostura, que convierten al plagio y la simulación, en sí mismos y sin finalidad ninguna, en verdadera obra de creación. En varias ocasiones, se ha señalado ya la filiación del extraño libro de Bolaño, recordando su deuda con las Vidas imaginarias (1896) de Marcel Schwob (conjunto de biografías apócrifas de personajes inventados y todos ellos perversos), los Retratos reales e imaginarios (1920) de Alfonso Reyes, la ya mencionada Historia universal de la infamia, o La sinagoga de los iconoclastas (1972) de J. R. Wilcock. A esta lista también podría añadírsele la obra de VilaMatas. Sin duda tanto este como Bolaño se ubican con sus obras en una concepción borgeana de la literatura muy frecuente en nuestros días. La estrategia utilizada por ambos autores en las dos novelas mencionadas no es exactamente la misma: si Vila-Matas inventaba anécdotas falsas (y poco creíbles) en relación con autores y obras verdaderas, Bolaño nos ofrece una galería de vidas absolutamente verosímiles de autores inventados. Pero, en ambos casos, estamos ante una estética de la impostura, o «poética de la simulación», como dio en llamarla el propio Vila-Matas (2008), que está dando no pocos ejemplos interesantes en la literatura española reciente.

En septiembre de 2010 la revista Quimera publicó un número de absoluta apariencia veraz pero que encerraba una sorpresa que no tardó en ser develada. La totalidad de la revista había sido escrita por el escritor Vicente Luis Mora, que se ocultaba tras los nombres de los colaboradores reales o inventados que firmaban las diferentes secciones. La falsificación llevada a cabo por Vicente Luis Mora en las páginas de Quimera, 322 (septiembre, 2010), escribiendo la totalidad del número y haciéndose pasar por otros, fue recibida por muchos como uno de los experimentos literarios más audaces de los últimos años. Obviamente, en este caso, el formato elegido para el experimento, las páginas de una revista real y muy conocida, garantizaba el impacto y la posibilidad de engañar a un mayor número de lectores. El mismo Mora confesó después en su blog cómo había llevado a cabo tan arriesgado proyecto. Durante meses se dedicó a inventar libros supuestos, poemas para que los poemarios pareciesen reales, argumentos y declaraciones apócrifas, traducciones falsas, irreales editoriales, «en un proceso abismante donde tenía que inventarme la escritura del crítico inexistente y también la del ficticio escritor reseñado» (Mora 2010). Para Mora, y estoy totalmente de acuerdo con esta afirmación, Quimera 
322 es una obra más de su bibliografía, una novela que, como alguien comentó en el blog del autor en el momento de su aparición, resultaba una curiosa inversión de Alba Cromm (2010): «de una falsa revista en formato libro, a un falso libro en formato de revista real» (en Mora, 2010).

También debió de engañar Juan Bonilla a muchos lectores, cuando dos años más tarde, publicó su extraño Catálogo de libros excesivos, raros o peligrosos que ha dado a la imprenta Juan Bonilla y edita la Universidad de Sevilla en 2012 (2012). Esta obra se nos presenta así desde su impostado título como un remedo de los antiguos catálogos de libros. La obra de Bonilla tiene una «Explicación» inicial, donde el narrador cuenta que, como consecuencia de la crisis económica y tras la pérdida de sucesivos empleos como colaborador de prensa, se vio obligado por pura supervivencia a ir deshaciéndose de su biblioteca, poniendo progresivamente todos sus ejemplares a la venta. A partir de esta crítica situación se le ocurrió al autor escribir las entradas o fichas informativas de aquellos libros de los que debía ir desprendiéndose. En esa misma nota, firmada por J.B., se explican, con mucha más trasparencia (quizás innecesaria) de la que encontramos en Vila-Matas o Bolaño, las intenciones que se esconden tras la inusual configuración del libro:

\footnotetext{
Los catálogos de libreros, desde hace mucho, son una lectura predilecta mía, y me parecía, viendo algunos de ellos, los que más se atrevían a añadir algo de parte de quien los redactaba, como impresiones personales aunque fueran apresuradas o citas de autores para demostrar la importancia del libro que se quería vender (cosa que los libreros ingleses hacen todavía mucho y los españoles aún nada), me parecía, digo, que proponían una plantilla estupenda para ser usada con otros fines: pensaba, por ejemplo, en una novela que fuera un catálogo de librero de viejo en el que cada entrada, al recorrer las características de los volúmenes que salían a la venta, permitiera al redactor entrometer señales personales, dónde compró el libro que ahora vendía, dónde lo leyó, cómo lo descubrió, y poco a poco, de entrada en entrada, fuera irguiendo una narración biográfica a través de los libros que iba describiendo (...) la mayor parte de las veces me dejaba llevar o por lo que recordaba del libro o por lo que creía saber del autor o, por lo que el anterior propietario se había dejado dentro del volumen (Bonilla 2012: 19).
}

La novela termina con un «Addendum» firmado por Miguel Albero, que contiene la reseña del Catálogo de libros excesivos, raros o peligros que ha dado a la imprenta Juan Bonilla y 
edita la Universidad de Sevilla en 2012 Primera edición. Ejemplar Intonso y fatigado, dedicatoria autógrafa del autor al autor del Addendum. Raro, más raro que un perro verde con botines. No se lo pierda.

Es decir, el libro de Bonilla contiene, a modo de juego metarreferencial, la reseña de sí mismo en forma de adenda. Cabría interpretar estas últimas páginas del libro de Bonilla como un convencional epílogo, pero quizás sería más acertado interpretarlo como paratexto apócrifo, y leerlo en realidad como parte de la novela experimental que nos propone Bonilla y no como un añadido ajeno. El mismo autor del epílogo alude al hecho de que, al incluir el catálogo en el catálogo «nos vemos inmersos en una de esas paradojas autorreferenciales»; estaríamos en suma ante el mismo «caso de los catálogos de las bibliotecas que incluyen el catálogo entre los libros de la biblioteca» (en Bonilla 2012:: 274). Continúa Albero afirmando que esta circunstancia convierte al libro de Bonilla en un «libro imposible», tan raro que no puede ser. Y, más aún, añade que Bonilla con este libro "ha conseguido hacer del catálogo un género literario», de igual modo que «hizo Borges con el prólogo» (en Bonilla 2012: 277).

Como ha demostrado Pérez Dalmeda en su tesis doctoral, la idea de hacer una novela autobiográfica o autoficcional con la forma del catálogo de libros rondaba a Bonilla desde hacía bastantes años, habiendo sido mencionada esa posibilidad en obras anteriores (Pérez Dalmeda 2015: 426). Demuestra, por otro lado, cómo Bonilla aprovecha para la escritura de las entradas de su catálogo muchos textos anteriormente publicados en otros libros, que son ahora leve o intensamente reescritos y modificados. Señala también esta autora el presumible desconcierto del lector ante esta obra, que no sabrá, aunque tampoco deba importarle, si realmente Bonilla vendió los libros que componen el catálogo o si «todo es un montaje ficcional para escribir esa autobiografía o autoficción en tantas ocasiones anunciada» (Pérez Dalmeda 2015: 427). Sea como fuere, el resultado es una obra que trata indiscriminadamente de los más variados asuntos, desde la reminiscencia de anécdotas personales, hasta numerosas reflexiones sobre estética, artistas y escritores, libros o incluso futbol.

Aunque no tengo dudas respecto a la filiación de esta obra dentro de esa estética borgeana de la impostura de la que venimos hablando, lo cierto es que la misma es catalogada en Wikipedia entre las obras ensayísticas del autor, y no entre sus obras narrativas. Cosa que no sucede con las obras citadas de Vila-Matas o de Bolaño, incluidas en ambos casos en la sección 
de «Novela». Pues bien, la ambigua recepción y la relativa falta de consenso que nos plantean obras como estas nos hace ineludiblemente más propensos a extender esa misma ambigüedad a la consideración de otras que hace unos años no nos planteaban ninguna duda respecto a su clasificación genérica.

Por supuesto una obra como el Diccionario de literatura (1995) de Francisco Umbral aparece siempre catalogado como auténtico diccionario ( $y$, sin duda, a pesar de sus números caprichos y arbitrariedades, lo es), pero a tenor de todo lo dicho hasta aquí tampoco nos costaría trabajo ubicarlo en ese atractivo espacio de indeterminación genérica donde voluntariamente se han querido situar todas las obras que comentamos en este artículo. Recordemos que Umbral, que dedicó precisamente su libro «A los que no leen diccionarios», confesaba en el prólogo que este diccionario era una obra hecha por encargo, pero que una vez aceptado el encargo, la malicia del escritor viejo tenía que «transformarlo en otra cosa, adaptarlo a lo que él quiere decir, más que a lo que quiere decir el editor» (1995: 9). Como en el resto de obras mencionadas, también en esta encontraremos en los paratextos claves y pistas interesantes para desvelar la impostura. La obra se cierra así con un «Epílogo (con negritas) o la subversión del diccionario» que contiene referencias a algunos autores supuestamente mucho más importantes y prestigiosos (otros no) que los recogidos en el corpus central del diccionario, donde cada uno tenía su entrada específica. Dicho epílogo se presenta así como «el levantamiento de los ficheros y los archivadores» (11), «la revuelta del libro contra su autor», «una cosa pirandelliana en un señor como yo -afirma irónico Umbral-, que no frecuenta nada a Pirandello» (10-11). El autor nos explica a este propósito que, de barajar y jugar tanto con los nombres, los datos, las fichas y las fechas, el archivo se le ha revuelto en «un tornado de nombres, personas, datos» (265). Ante tal desbarajuste, como no podía ser de otra manera, concluye Umbral que le gusta «el barullo que se ha armado» (265-266). Y más adelante: «Este es un libro donde se cuenta la literatura española que uno ha vivido» (272). Ese «cuenta», en cursiva en el original, nos da una clave de interpretación para su diccionario en el terreno de lo ficcional verosímil. Al tiempo que nos invita a cuestionar la credibilidad de todo manual, diccionario o enciclopedia que se tome por tal. Tras todos estos juegos asoma ese conocido axioma de la Posmodernidad que nos lleva a la consideración de la Historia como Relato.

Umbral, por supuesto, tampoco desperdicia la ocasión para parodiar la sistematicidad 
rigurosa habitual en el modelo convencional de los diccionarios, generalmente organizados por orden alfabético:

\begin{abstract}
Claro que el elemental, escolar, tierno y férreo orden alfabético desdibuja un poco todo esto, pues aquí no nos atenemos al paso del tiempo, sino al paso colegial y practicón de las letras. Pero yo he escrito el libro con perspectivismo de historiador, siguiendo el curso de nuestra literatura contemporánea, que tiene su lógica y secuencia para quienes creemos algo en la Historia y su mecánica reto/respuesta, ya diagnosticada por Toynbee. Luego me he limitado a coger los nombres y ponerlos por orden alfabético de apellidos, así como las voces (pocas, pero necesarias) que se mezclan en el libro. Ya ve qué fácil es hacer un diccionario (1995: 10-11).
\end{abstract}

A partir de la irónica reflexión de Umbral, quizás podríamos concluir que la recurrencia al motivo de la Historia, el Manual o el Diccionario para enmascarar ficciones que terminan por deconstruir a aquellos, parece encaminada a cuestionar la falacia e impostura que conlleva todo corpus cerrado y limitado. En casi todas las obras aludidas, la disposición externa de las diferentes partes de la novela se basa en el listado, en las entradas ordenadas alfabéticamente (en el caso de la novela de Bonilla) o temáticamente (en el caso de la novela de Bolaño). El autor echa mano de un determinado criterio para ordenar las secciones, y ese criterio (externo a la propia ficción) se nos ofrece como antagónico de la relación causal (y no casual) que se presupone entre los sucesivos capítulos de una novela, entendida esta ahora en un sentido más convencional. En la novela-catálogo de Juan Bonilla es el sistema alfabético el que establece el orden de las diferentes entradas. Ningún sistema tan aleatorio como este. Y por ello también ninguno más útil para poner en evidencia sus propias deficiencias. Al leer la novela de Bonilla el lector quedará desconcertado, si es que espera de verdad encontrar una novela, con los bruscos cambios de tema, época y autor que va imponiendo el orden alfabético con el que se organizan las entradas. A este respecto resulta interesante la propuesta de Jara Calles que habla de «escritura en listas», como un nuevo paradigma de escritura de la narrativa actual, frente al más habitual modelo de «escritura fragmentaria» (Calles 2014)².

Algo diferente es en relación con esto el caso de Historia abreviada de la literatura portátil, donde ya no encontramos el paradigma de las listas, capítulos o secciones sucesivos que respondan a un criterio externo y objetivo de ordenación. En la obra de Vila-Matas, como

\footnotetext{
${ }^{2}$ Calles habla de una brecha cualitativa entre los textos configurados de ese modo que ella denomina escritura en listas y aquellos concebidos bajo una percepción fragmentada de la realidad: «Mientras en estos opera una mostración espacial del texto, por la conjunción de distintos fragmentos textuales, en los primeros emerge una complejidad (que no dificultad) discursiva, que a su vez constituye una superación de ese modelo de fragmento — porque fragmento ¿respecto a qué?—》 (Calles 2014: 120).
} 
ha señalado Pozuelo Yvancos, «el ensamblaje de sus contigüidades y toda la estructura leve de sus acciones en modo alguno se rige por la idea de necesidad, antes al contrario, por la de azar o gratuidad» (2010: 167-168). Y, efectivamente, a partir de esta novela en el resto de obras del autor se impondrá siempre el azar, el deambular de manera ociosa y sin aparente finalidad, frente a la relación causal entre capítulos sucesivos. Este tipo de estructura (o ausencia de ella) se ha relacionado asimismo con el modelo de la red, «caracterizado fundamentalmente por la ausencia de jerarquías significativas: en la red todo ocupa un mismo plano, de naturaleza abierta y procesual. Las redes no tienen ni arriba ni abajo, ni dentro ni fuera; están siempre haciéndose» (Oñoro Otero 2015: 114). A partir del modelo de la red, en esta novela la historia literaria «aparece como un gran texto polifónico en el que no es posible fijar unidades o centros de anclaje significativos» (Oñoro Otero 2015: 116).

Pero Pozuelo Yvancos va más lejos aún en relación con la utilización de la imagen de la red para explicar este modelo estructural de relato, asegurando que «el discurso en las novelas de Vila-Matas se asemeja a un tejido de links, de vínculos que nos permiten navegar, varios años antes de Internet» (2010: 169). Me interesa ahora destacar esta sugerente imagen que compara el relato de Vila-Matas con una navegación por Internet. Es cierto que si tenemos en cuenta la fecha en la que se publicó Historia abreviada de la literatura portátil —hablamos del año 1985— hay que admitir que la relación de la estructura narrativa con Internet sólo puede entenderse en términos prospectivos, pero en algunos de los últimos libros del autor, escritos ya en una época en la que también a Vila-Matas hay que suponerle internauta, se ha introducido un motivo temático en el que merece la pena que ahora nos detengamos. Me refiero a momentos puntuales en los que el narrador alude al acto cotidiano de navegar por Internet, siendo los casuales hallazgos futo de sus navegaciones el motivo desencadenante de un nuevo tema a desarrollar. De esta manera, lo que antes era un deambular ocioso e injustificado, sin dejar de serlo, parece ahora a veces motivado por el recorrido que se realiza de la mano del navegador de Internet. Así, por ejemplo, lo encontramos en Kassel no invita a la lógica (2014), donde el narrador alude al hallazgo en Google de una versión en inglés de la conferencia que acaba de pronunciar en la Documenta de Kassel (Vila-Matas 2014: 295). Quizás estemos ante una nueva estrategia para introducir contenidos ensayísticos, que a su vez parece ponernos en la pista de otro modelo estructural cada vez más frecuente en la narrativa contemporánea. 


\section{Addenda: La Novela-Wikipedia}

Mal que les pese a muchos, Wikipedia es hoy la gran Enciclopedia. Los viejos diccionarios han perdido todo su sentido y todas nuestras necesidades de información se satisfacen en Internet. Al mismo tiempo, nuestra búsqueda parece haberse vuelto más anárquica y azarosa, menos sistematizada $y$, muchas veces, sin finalidad aparente. El viejo libro de referencia, cerrado y sistematizado en su estructura, por definición, ha sido reemplazado por la gran obra abierta, multiforme e inasible que nos ofrece Google. La manera en la que se introduce el ensayo y lo ensayístico en algunas novelas españolas recientes quizás esté metaforizando esa evolución. El conocimiento parece haberse convertido en nuestra época en sinónimo de búsqueda y el buscador de Google en el valedor de todo nuestro conocimiento. Varias novelas españolas recientes construyen su argumento a partir del motivo de la búsqueda en Google. Así, por ejemplo, la novela de Germán Sierra Intente usar otras palabras (2009) nos remite al popular buscador ya desde el propio título. En esta obra no sólo el personaje protagonista busca y se busca de forma obsesiva en Google, sino que además el buscador de Internet funciona como motivo inspirador de una determinada estructura extremadamente fragmentaria. En esta se alternan de manera azarosa capítulos más narrativos, que van construyendo una historia de desamores y búsqueda de identidades, con otros de carácter ensayístico y sin aparente conexión con aquellos, que reproducen supuestos post del blog de algunos de los personajes de la novela. A lo largo de esta encontramos también ocasionales repeticiones de algunos fragmentos, lo que nos hace pensar en una navegación real por Internet, en la que no es raro que pasemos más de una vez por el mismo sitio.

En realidad los textos ensayísticos que se presentan en la novela con aparente origen digital son falsos, sin existencia real fuera de la novela (si nos podemos fiar de nuestra propia búsqueda en Google), pero de absoluta apariencia veraz. Esa apariencia hace dudar a los lectores, que se verán seguramente tentados a comprobar la existencia de dichos textos en el buscador de Internet. De esta manera Google cumple con una doble función en esta obra: como motivo temático recurrente e inspirador de la trama y la estructura y como instrumento externo a la misma que nos permite la identificación de la veracidad o falsedad de los documentos que la integran. Como se repite en la misma novela, «La búsqueda es la forma contemporánea de la fe. Intente usar otras palabras» (Sierra 2009: 51). Si Google tiene hoy en día la última palabra respecto 
al «ser o no ser» de cualquier persona y objeto, esa certeza parece subyacer en las propuestas narrativas que vamos a comentar. En todas ellas se dotará a Google del valor de oráculo e icono de nuestra búsqueda, al tiempo que de archivo de la experiencia contemporánea.Esta idea se plasma todavía de una manera mucho más explícita en Crónica de viaje (2009) de Jorge Carrión. Toda la obra se vale de la reproducción visual de lo que vemos en la pantalla del ordenador a partir de unas determinadas búsquedas en diferentes aplicaciones reales o imaginadas de Google. Esas capturas de pantallas son simuladas y ficticias. Los textos que ofrece Google no son reales; son un montaje premeditado que nos lleva a una reflexión acerca del asunto de la emigración y, más concretamente, la emigración de andaluces a Cataluña durante el Franquismo, lo que le da a esta obra un cariz ensayístico y autobiográfico. Jorge Carrión explica así los motivos que le Ilevaron a construir su libro artefacto Crónica de viaje: «entendí que todas las búsquedas de nuestra época, también las que tienen que ver con nuestra identidad personal, pasan por Google.» (2014: s.p.). Y más adelante: «Se trataba de apropiarme de Google, de quitarle sus colores de parque temático, de violentarlo, de ficcionalizarlo; para que sus estructuras narraran, mediante datos y documentos, varias historias convergentes sin un gramo de ficción» (2014: s.p.). A partir de la declaración de intenciones confesada por el propio autor, una vez más me ha interesado comprobar cómo se clasifica la obra en Wikipedia, descubriendo que tampoco esta va a aparecer en el apartado de «Novela», sino en el de «Literatura de viajes». Y lo cierto es que nada estaría más alejado de esa convencional etiqueta genérica que la obra que acabamos de comentar.

También las fragmentarias y rizomáticas estructuras novelísticas de Agustín Fernández Mallo (que sistemáticamente combinan fragmentos narrativos inconexos con otros de carácter ensayístico, de autoría tanto propia como ajena) han sido en numerosas ocasiones puestas en relación con una plasmación metafórica de lo que ocurre en la red (Pozuelo Yvancos 2007; Ors 2007). Nocilla Dream, la primera de las novelas de su popular trilogía, terminaba (al igual que las obras de Borges, Vila-Matas o Bolaño) con una lista de «Créditos», donde se refería el origen de las citas usadas por orden de aparición. Pero, como en el caso de sus predecesores, parte de esos créditos son falsos. No en vano Fernández Mallo alude en este mismo epílogo al concepto de «docuficción» (Martínez Rubio 2014) como estrategia compositiva de su novela. Por otro lado, más allá de esa utilización de las redes como fuente inspiradora de una determinada estructura, 
encontramos también una utilización muy explícita del famoso buscador de Internet para estructurar la tercera de las novelas de su trilogía. Vemos así que, en efecto, el índice de Nocilla Lab (2009) nos anuncia tres secciones tituladas: «Motor automático de búsqueda», «Motor automático», «Motor (Fragmentos encontrados)». La trama, que aunque fragmentariamente se ha ido desarrollando, se interrumpe de pronto en la segunda sección para reproducirse «Por orden cronológico» una sucesión de fragmentos encontrados, algunos de carácter ensayístico y todos ellos de autoría ajena (Fernández Mallo 2009: 88-90). Asimismo, algunos textos de Fernández Mallo que encontramos en libros posteriores a este parecen estructurarse a partir de una navegación cualquiera por Internet. Así, por ejemplo, en el capítulo de Limbo (2014) titulado «Eco, él», el narrador divaga sobre heterogéneos asuntos, estableciendo links a través de fotografías que va diseminando en el texto. Supuestamente se trata de fotografías que el narrador dice guardar en un archivo de imágenes que desde hace años va llenando con cosas que captura en la red (Fernández Mallo 2014: 82) o que va buscando directamente en Google al hilo de sus reflexiones (Fernández Mallo 2014: 87).

Otro autor que nos ofrece buenos ejemplos en relación con este modelo estructural de novela es Alberto Olmos. En Ejercito enemigo (2011) el narrador utiliza obsesivamente el buscador y al hilo de sus búsquedas y sus hallazgos se va desarrollando la trama (Olmos 2011: 200-201). Pero quizás todavía más interesante en relación con la estrategia de la falsificación y la impostura resulte un libro muy poco conocido de este escritor: Algunas ideas buenísimas que el mundo se va a perder (2009). En la portada del mismo, Alberto Olmos -conocido autor ya en el año 2009 de unas cuantas novelas en general bien acogidas por la crítica- figuraba como «editor» y no como «autor». Su labor en este caso aparentaba ser la del antólogo que rescata y compila una selección de textos de supuesta autoría ajena relacionados a partir de un motivo común, facilitando así el trabajo a los lectores. El común denominador de los textos seleccionados era en este caso el origen digital de los mismos: posts de blogs, e-mails, sms, spam. También como en las verdaderas antologías, la selección iba acompañada de una «Nota» firmada por el editor, donde se explicaban los motivos y el proceso de su búsqueda, así como, una vez más, una lista de «Créditos», en la que se aclaraba el origen de los textos seleccionados y se daba cuenta de la identidad de sus verdaderos autores: 


\begin{abstract}
Algunas ideas buenísimas que el mundo se va a perder es una obra colectiva fruto de una impresión personal. En un principio, la idea apuntaba exclusivamente a los blogs, esos sites donde tantos y tantos aspirantes a escritor cuelgan sus creaciones para darles mayor difusión y batirse un poco con la opinión ajena. Sin embargo, analizados más en detenimiento, estos blogs netamente literarios me resultaron casi antiinternautas: no había mucha diferencia entre su contenido y el que, tradicionalmente, esperaba su oportunidad (en forma de manuscrito o mecanoscrito) en el cajón de un joven letraherido. Primeramente, me di cuenta de que para realizar una novela a partir de Internet habría que privilegiar los textos que tuvieran más de documento que de literatura, y que la literatura que haríamos con ellos sería una literatura que no se sabe tal. Era más jugoso el testimonio del hoy (apelaciones a la tecnología y las nuevas formas de comunicación, jeremiadas y quejas sociales varias) que la calidad literaria (cuentos correctos inéditos hay muchos en la Red). Después, comprendí que antologar posts interesantes era demasiado simple, y que una obra que quisiera reflejar "lo que pasa en Internet» tenía que seguir las reglas del medio e incluir todo el paratexto con que habitualmente nos tropezamos al navegar: mails, spam, mensajería instantánea, avisos robóticos (Algunas ideas buenísimas que el mundo se va a perder, 297-298).
\end{abstract}

A tenor de todo lo explicado por esa voz narradora que identificamos con Olmos, en este caso no es de extrañar que Wikipedia incluya el libro en la sección de «Ediciones» y no en la de «Novela». Pero, paradójicamente, obsérvese que en el fragmento reproducido sí se llega a calificar a este libro de «Novela». Dicha novela, si es que podemos considerarla como tal, sería una obra «de creación individual», hecha a partir del procedimiento de corta y pega, es decir a partir de la apropiación de textos escritos supuestamente por otros autores, que son substraídos de su contexto original y natural (la Red) e incorporados ahora en un nuevo medio que, por supuesto, les confiere también otro significado. Por otro lado, interesa destacar de la declaración de intenciones de Olmos esa voluntad de otorgar estatuto literario precisamente a aquello «que no se sabe tal».

En cualquier caso, es probable que una vez más lo declarado en el paratexto pudiera estar encubriendo una impostura. Si admitiéramos que los textos son realmente de autoría ajena, y que con ellos se pretende hacer una novela, hubiera sido deseable que Olmos hubiese Ilevado más lejos su experimento atreviéndose a quitar la aclaración «edición de» que precede a su nombre en la portada. Si, por el contrario, admitiéramos que los textos estuvieran escritos por el mismo Olmos, siendo tan sólo falsamente ajenos (posibilidad que no descarto tras mi frustrada búsqueda de dichos textos en Google), la audacia estaría precisamente en haber puesto en la 
portada la advertencia de «edición de».

Sea como fuere, la apropiación del texto (falsa o verdaderamente) ajeno y su visible incrustación en una obra propia que, lejos de disimular el «sistema de producción», se regodea en hacérnoslo tan visible, parece escenificar el desengaño escéptico ante la búsqueda de la verdad en la materia prima, en un supuesto texto original (que no existe). Todos estos autores, con su extraña exhibición de textos encontrados en Google, nos ofrecen novelas que se constituyen a partir del «burdo» procedimiento del corta y pega. Y con ello parecen estar hablándonos de la imposibilidad de discernir entre la copia y el supuesto original que la generó. Como Pierres Menards de nuestros días, hacen del plagio y la falsificación una inquietante obra de arte.

Me gustaría terminar aclarando que, en mi opinión, el resultado de nuestras pesquisas (las de lectores y críticos) acerca de la veracidad o falsedad de las citas, autores y textos incluidos en estas novelas no me parece excesivamente relevante. Mayor interés tiene la capacidad que tienen estas obras para hacernos dudar. Decía más arriba que los casos más interesantes que nos ofrece la artimaña narrativa que estudiamos en este artículo son aquellos en los que el autor todavía consigue engañarnos o, al menos, dotar de cierta ambigüedad nuestra recepción de la obra. ¿Es Algunas ideas buenísimas que el mundo se va a perder una antología de falsos o verdaderos textos encontrados?; los post de blog que incluye Germán Sierra en su novela, ¿tienen existencia real fuera de la misma?; los artículos que reproduce Carrión ¿tuvieron alguna vez presencia en Google?; ¿son falsas o verdaderas cada una de las citas que van conformando el tejido textual de los libros de Vila-Matas?; alguno de los autores que retrata Bolaño, ¿̇iene su correspondencia en clave paródica en la vida real?... Todas ellas parecen dudas legítimas a la hora de enfrentarnos a la lectura de estas novelas. Y, precisamente, sólo mientras la incertidumbre y la duda permanezcan (salvándonos del tedio de lo previsible), ese juego tan cultivado de la impostura seguirá consiguiendo para la novela resultados admirables. 


\section{Bibliografía}

ALBERCA, Manuel: El pacto ambiguo. De la novela autobiográfica a la autoficción. Madrid: Biblioteca Nueva, 2007.

AVILÉS, Javier: «La literatura nazi en América, de Roberto Bolaño», El lamento de Portnoy (16/07/2005). En: http://ellamentodeportnoy.blogspot.com.es/2005/05/la-literaturanazi-en-amrica-de.html.

BELMONTE SERRANO, José \& Pedro GUERRERO RUIZ: «La escripintura según José Saramago: Manual de pintura y caligrafía», Romance Quarterly, 51:4 (2004), 297-303. En: http:// dx.doi.org/10.3200/RQTR.51.4.297-303.

BOLAÑO, Roberto: La literatura nazi en América. Barcelona: Anagrama, 2010.

BONILLA, Juan: Catálogo de libros excesivos o peligrosos que ha dado a la imprenta Juan Bonilla y edita la Universidad de Sevilla en mmxii. Sevilla: Universidad de Sevilla, 2012.

BORGES, Jorge Luis: Historia universal de la infamia. En Obras completas. I. Barcelona: RBAInstituto Cervantes, 2005, pp. 287-345.

CALLES, Jara: «Escritura en listas o cómo la noción de fragmento se presenta susceptible de revisión en la escritura española contemporánea», en Marco Kunz y Sonia Gómez (eds.), Nueva narrativa española. Barcelona: Linkgua, 2013, pp. 117-133.

CARRIÓN, Jorge: Crónica de viaje. Madrid: Aristas Martínez, 2014

FERNÁNDEZ MALLO, Agustín: Nocilla Dream. Madrid: Candaya, 2006. -Nocilla Lab. Madrid: Alfaguara, 2009

-Limbo. Madrid: Alfaguara, 2014.

JACARILLA, Marla: «Presentación» de Manual de instrucciones para interpretar falsas novelas, en Multiverso. Videoarte. Fundación BBVA, 2016. En: http://multiverso-videoarte-fbbva. es/manual-de-instrucciones-para-interpretar-falsas-novelas/.

MARTíNEZ RUBIO, José: «Autoficción y docuficción como propuestas de sentido. Razones culturales para la representación ambigua», Castilla. Estudios de Literatura, 5 (2014): 26-38.

MORA, Vicente Luis: Quimera 322, Quimera, 322 (septiembre 2010).

-«El hoax de Quimera». Diario de lecturas (20-09-2010). En: http://vicenteluismora. 
blogspot.com.es/2010/09/el-hoax-de-quimera.html).

OÑORO OTERO, Cristina: Enrique Vila-Matas. Juegos, ficciones, silencios. Madrid: Visor, 2015.

OLMOS, Alberto: Algunas ideas buenísimas que el mundo se va a perder. Madrid: Caballo de Troya, 2009.

--Ejército enemigo. Barcelona: Mondadori, 2011.ORS, J.: «Sueños poéticos de la estética blog», La Razón (9 de marzo de 2007).PAVIC, Milorad: Diccionario jázaro. Barcelona: Anagrama, 2000.

PÉREZ DALMEDA, Esther: Ficción y reescritura en la narrativa breve de Juan Bonilla (tesis doctoral). Universidad de Valladolid, 2015.

POZUELO YVANCOS, José María: «Llega la estética del Blog», $A B C$ De las Artes y las Letras (sábado, 6 de enero de 2007).

-Figuraciones del yo en la narrativa. Javier Marías y E. Vila-Matas. Valladolid: Cátedra Miguel Delibes-Universidad de Valladolid, 2010.

RODRÍGUEZ DE ARCE, Ignacio: «La literatura nazi en América de Roberto Bolaño: imitatio caricatural y lectura paródica de la crítica literaria», Itinerarios, 9 (2009), pp. 23-34.

SARAMAGO, José: Manual de pintura y caligrafía. Madrid: Alfaguara, 1999.

SIERRA, Germán: Intente usar otras palabras. Barcelona: Mondadori, 2009.

UMBRAL, Francisco, Diccionario de literatura. España 1941-1995: de la Posguerra a la Posmodernidad. Barcelona: Planeta, 1995.

VILA-MATAS, Enrique: Historia abreviada de la literatura portátil. Barcelona: Anagrama, 1985.

-Kassel no invita a la lógica. Barcelona: Seix Barral, 2014.

-«Intertextualidad y metaliteratura: alocución en Monterrey», Texto leído en la Cátedra Anagrama de la Universidad de Monterrey. México, 1 de agosto de 2008. En: http:// www.enriquevilamatas.com/textos/textmonterrey.html. 